\title{
LA PROFESIÓN Y LOS VALORES MILITARES EN ESPAÑA
}

\author{
JOSEP BAQUÉS \\ Universidad de Barcelona
}

\author{
PALABRAS CLAVE ADICIONALES \\ Fuerzas Armadas, Civilinización, modelo \\ institucional/ocupacional, Posmodernidad.
}

\section{ADDITIONAL KEYWORDS}

Armed Forces, Civilinization, Institutional/

Occupational Model, Post-modernity.

RESUMEN: En este trabajo se analiza la percepción que los oficiales del ejército español tienen hoy en día de su profesión, así como de los valores específicos que la impregnan. Para ello, se parte del proceso civilinizacional descrito por Janowitz, se utiliza el enfoque popularizado por Charles Moskos, dado que nos permite distinguir entre el modelo institucional, el ocupacional y algunas fórmulas híbridas ubicadas entre ambos, y se plantean algunos interrogantes sobre la adaptación a las circunstancias de la posmodernidad. De las fuentes empleadas se deduce que los militares españoles desean avanzar desde lo institucional hasta alguna fórmula mixta, que incluya valores ocupacionales. Pero sin que ello suponga una renuncia definitiva a los rasgos que conforman el ethos tradicional de las Fuerzas Armadas.

\begin{abstract}
This paper analyses the perception that the Spanish officers have today about their profession, as well as specific values which pervade it. In order to achieve this it starts with civilinizational process described by Morris Janowitz. Next, it uses the slant popularized by Charles Moskos, because it allows one to distinguish between the institutional model from the occupational one, and from some hybrid types among them both. And finally, it raises some questions about the posmodern issues. It is deduced from the sources employed that Spanish Armed Forces look forward to advancing from the institutional to some other mixed form, which includes occupational values and posmodern trends. Not meaning a definite resignation of the features that suppose the traditional ethos of the Armed Forces.
\end{abstract}

E-mail: jbaquesq@ub.edu

Revista Internacional de Sociología (RIS)

Tercera Época, No 38, Mayo-Agosto, 2004, pp. 127-146. 


\section{MARCO CONCEPTUAL Y METODOLÓGICO}

En las siguientes páginas pretendo ofrecer una visión de conjunto sobre la percepción que los oficiales españoles de los tres ejércitos poseen acerca de algunos temas clave para las relaciones civiles-militares. Concretamente, acerca del modelo de profesión militar, lo cual supone indagar también en los valores que impregnan a dicho colectivo, dada la correlación existente entre ambas cuestiones.

Se trata, por lo demás, de un trabajo acotado en el tiempo (las fuentes se centran en el período democrático) que se nutre de una investigación más amplia. Las opiniones recogidas lo son de oficiales, jefes y generales (o almirantes) pertenecientes a dichos ejércitos. No se incluyen, por lo tanto, opiniones de suboficiales y tropa (esta última mayoritariamente de reemplazo, en el período de referencia). A su vez, el material con el cual se ha trabajado procede, sobre todo, de lâs revistas de los Estados Mayores de cada uno de los tres Ejércitos (Ejército; Revista General de Marina y Revista de Aeronáutica). Asimismo, a fin de completar la investigación y corregir posibles sesgos derivados de esas fuentes, se han añadido los comentarios aparecidos respecto al particular en otras publicaciones, que no pretenden ser el órgano de expresión de cada uno de ellos, desde la Revista Española de Defensa, hasta diversas monografias.

El marco teórico del que parte este análisis tiene como referente lejano, pero necesario, la obra del sociólogo norteamericano Morris Janowitz, especialmente en lo que concierne a la exposición del proceso por él definido como de civilinización. El interés de este concepto radica en que describe un proceso de convergencia creciente (a modo, pues, de tendencia) entre los valores civiles y los valores militares. De hecho, se trata de un proceso en el cual los primeros estarían influyendo sobre los segundos, debido a unas causas claramente identificadas por el autor. Esas causas van desde el impacto de las nuevas tecnologías, hasta la diversidad de facetas o campos en los que debe especializarse el "guerrero" moderno (logística, sanidad, gestión de recursos humanos, ingenierías -en plural - e incluso economía, derecho o sociología). También se considera relevante la progresiva disminución de la endogamia en las academias, así como la apertura de los planes de estudio de dichos centros de formación a pautas similares a las vigentes en el sistema universitario. Aunque, en este último caso, debe reconocerse que Janowitz nunca cuestiona la necesidad de que dichos planes de estudio sigan siendo respetuosos con los requerimientos específicos de una formación profesional que tiene mucho de peculiar (Janowitz, 1990, especialmente capítulos 5, 6, 7, 9 y 11).

En efecto, tanto el fenómeno, muy de nuestro tiempo, de la guerra a distancia, como el tipo de actividad a desarrollar en el cumplimiento de sus funciones son acicates que operan en la misma dirección: el referente del militar de la segunda mitad del siglo XX (como mínimo), en los países más desarrollados (empleando como paradigma el caso norteamericano) no lo sería tanto el guerrero "heroico" de antaño y sí, por el contrario, el profesional cualificado (civil) de hogaño. 
Charles Moskos, discípulo del anterior, dio un paso más al describir dos grandes modelos o tipos ideales (en sentido weberiano) de Fuerzas Armadas: el modelo institucional y el modelo ocupacional.

El primero se caracteriza por mantener buena parte del ethos militar tradicional. Por tanto, está basado en la primacía de la vocación, en la definición de unos objetivos que trascienden los intereses individuales de sus miembros y en la presencia de un código ético estricto, bajo cuya égida se fomentan virtudes como la disciplina, el espíritu de sacrificio o el honor.

El segundo, por el contrario, se le opone en muchos aspectos: prioridad del interés personal; reclutamiento y sistema de recompensas basados en los incentivos económicos; incremento de las áreas de intersección con los valores de la población civil, etc. (Moskos y Wood, 1991: 43 y 45). Ni que decir tiene que este segundo modelo es el más próximo al concepto de civilinización de las FAS constituyendo, de alguna manera, una recodificación del mismo. El cuadro 1 puede ayudar a la comprensión de las características de los dos modelos propuestos por Moskos.

La elevada capacidad expositiva del enfoque de Moskos ha hecho que me decante por su aprovechamiento a fin de ubicar en el paradigma conocido como I/O (Institucional/Ocupacional) a los oficiales de nuestros tres ejércitos cuyas opiniones son objeto de estudio en las siguientes páginas.

Realmente, se trata de una aproximación que bien podría comprenderse en términos diacrónicos. En efecto, durante muchos años las Fuerzas Armadas (españolas y de tantos otros países) han venido funcionando de acuerdo con lo que aquí denominamos modelo institucional. El reconocimiento de este hecho es un lugar común en la obra de Janowitz y de Moskos. Sin embargo, también coinciden en señalar que, a medida que van pasando los años, podemos ir identificando por doquier una mayor tendencia a aceptar algunas de las implicaciones del modelo ocupacional. Piénsese que incluso la última obra coordinada por Moskos enfatiza este hecho. En efecto, a pesar de la novedad incorporada bajo el muy llamativo rótulo de The posmodern military, allí también se recuerda que, en el fondo, "la tendencia dominante conlleva la difuminación de la demarcación existente entre las entidades civiles y militares, tanto en sus aspectos estructurales como en los culturales" (Moskos, 2000: 11). En qué grado y de qué manera dependerá de cada sociedad.

$\mathrm{Ni}$ que decir tiene que el problema, definido en clave sociológica, tiene mucho que ver con las distancias que cada uno de estos modelos mantiene en relación con los valores sostenidos por el resto de la ciudadanía. No deja de ser significativo que estudios recientes hayan demostrado que el apego de la población a un determinado sentimiento patriótico -e incluso la manifestación de su simpatía hacia las Fuerzas Armadas, planteada en abstracto-no está reñido con el desapego hacia los elementos centrales del ethos castrense propiamente dichos. Piénsese en un caso típico, como la "disposición a luchar por defender 
RIS

REVISTA INTERNACIONAL DE SOCIOLOGÍA

Cuadro 1

Organización social militar

a) Incentivos hacia la profesión:

\begin{tabular}{|l|l|l|}
\hline & Mod. Institucional & Mod. Ocupacional \\
\hline Legitimidad & Valores normativos & Economía de mercado \\
\hline Consideración social & $\begin{array}{l}\text { Estima basada en nociones } \\
\text { de servicio }\end{array}$ & $\begin{array}{l}\text { Prestigio basado en el nivel } \\
\text { de compensación }\end{array}$ \\
\hline $\begin{array}{l}\text { Atractivos convocatoria } \\
\text { reclutamiento }\end{array}$ & $\begin{array}{l}\text { Cualidades del carácter; } \\
\text { orientación estilo de vida }\end{array}$ & $\begin{array}{l}\text { Paga elevada; } \\
\text { entrenamiento técnico }\end{array}$ \\
\hline
\end{tabular}

b) Recompensas profesionales:

\begin{tabular}{|l|l|l|}
\hline & Mod. Institucional & Mod. Ocupacional \\
\hline Bases de compensación & $\begin{array}{l}\text { Grado y veterania, no limitado } \\
\text { por la graduación }\end{array}$ & $\begin{array}{l}\text { Escasez de efectivos; reducida } \\
\text { por la graduación }\end{array}$ \\
\hline Modo de compensación & Mucho en especie o diferido & $\begin{array}{l}\text { Salario y otros incentivos } \\
\text { económicos }\end{array}$ \\
\hline $\begin{array}{l}\text { Situación una vez finalizado } \\
\text { el servicio }\end{array}$ & Subsidios de veteranos & Igual que el civil \\
\hline
\end{tabular}

c) Régimen laboral:

\begin{tabular}{|l|l|l|}
\hline & Mod. Institucional & Mod. Ocupacional \\
\hline Papel asignado & $\begin{array}{l}\text { Difuso, generalista/ } \\
\text { especialista }\end{array}$ & Específico \\
\hline Evaluación de resultados & Holística y cualitativa & Segmentada y cuantitativa \\
\hline Sistema legal & $\begin{array}{l}\text { Justicia militar; gran poder } \\
\text { sobre el individuo }\end{array}$ & $\begin{array}{l}\text { Justicia ordinaria/civil; escaso } \\
\text { poder vs. individuo }\end{array}$ \\
\hline
\end{tabular}

d) Implicaciones sociales:

\begin{tabular}{|l|l|l|}
\hline & Mod. Institucional & Mod. Ocupacional \\
\hline Cónyuge & $\begin{array}{l}\text { Integrado en la comunidad } \\
\text { militar }\end{array}$ & $\begin{array}{l}\text { Separado de la comunidad } \\
\text { militar }\end{array}$ \\
\hline Residencia & $\begin{array}{l}\text { Adyacente al trabajo; vivien- } \\
\text { das militares }\end{array}$ & $\begin{array}{l}\text { Separación del lugar de tra- } \\
\text { bajo; viviendas civiles }\end{array}$ \\
\hline Campos de referencia & "Vertical"; dentro de las FAS & $\begin{array}{l}\text { "Horizontal" (en su caso: } \\
\text { ocupaciones fuera Ejército) }\end{array}$ \\
\hline
\end{tabular}

Fuente: Moskos, 1991: 44 y elaboración propia. 
el país" (Díez Nicolás, 1999: 115). De acuerdo con los datos e interpretaciones del autor citado, ese desapego no sería aleatorio, sino, más bien, consecuencia del paulatino reforzamiento de una mentalidad pacifista. Investigadores de otros países razonan en términos similares, lo que prueba la consistencia de dichas influencias en el día de hoy. Sin ir más lejos, Moskos y Burk advierten que, en la sociedad civil de hoy, "las viejas verdades son cuestionadas en lugar de ser aceptadas. Pocas cosas quedan, si es que alguna, que pelean una autoridad tan grande como para que la gente esté dispuesta a acatarla" (Moskos y Burk, 1994: 143). Asimismo, es relevante el hecho de que cuanto mayor es el nivel de vida y la posición social de los entrevistados, menor es la valoración obtenida por las Fuerzas Armadas (Díez Nicolás, 1999: 113-114 y 173-174, respectivamente). Sobre todo porque eso pone de relieve que quienes más contribuyen a definir el referente de los militares "ocupacionales", en función del tipo de actividad desarrollada, son, a la postre, los que más distancias marcan con respecto a la institución militar entendida en su formato más clásico.

Pero el problema planteado en este análisis es bastante más profundo. Sobre todo porque también tiene que ver con el grado de cohesión interna alcanzado en el seno de las Fuerzas Armadas. Porque si bien el impacto de las pulsiones ocupacionales tiene bastante de inevitable, habrá que ver el modo en que se integra en una organización, la militar, que arranca de otros presupuestos, así como el grado de receptividad existente, sin incurrir en prejuicios de ningún tipo.

Ahora bien, antes de seguir avanzando es preciso hacer un matiz de importancia: el planteamiento teórico de Moskos añade un plus de complejidad. A su entender, en efecto, es viable un tercer modelo, modelo por él definido como "híbrido" o "plural". Su principal característica reside en que algunas unidades o Cuerpos (especialmente los combatientes) tenderían a mantener - y hasta a aumentar - su bagaje institucional. Por el contrario, el resto de unidades (algunos especialistas, los Cuerpos comunes, unidades logísticas y de apoyo, etc.) estarían abocadas hacia el modelo ocupacional. Con ello, las Fuerzas Armadas de un determinado país serían capaces de integrar, a su manera, elementos propios de uno y otro modelo.

Es más, Moskos opina que estas hibridaciones no serían la excepción, sino la regla, al menos en los últimos años del siglo XX. De este modo, a la vez que se tenderían puentes con los valores más propios de la sociedad civil, todavía podría sostenerse un núcleo duro militar como depositario de las más rancias tradiciones de las Fuerzas Armadas. En todo caso, los modelos puros siguen siendo factibles (aunque cada vez menos). Por otro lado, es preciso considerar ante qué tipo de mixtura nos encontramos porque, en función de cada sociedad, puede adoptar formas diversas con mayor o menor peso de unos u otros elementos. 


\section{ANÁLISIS DEL CASO ESPAÑOL}

De lo dicho hasta ahora se deduce que el punto de partida para el estudio del estado de la cuestión en las Fuerzas Armadas de cualquier país, en este fin de siglo, es la perspectiva institucional. En efecto, históricamente es anterior a la introducción de elementos propios del modelo ocupacional y, de hecho, al menos en principio, constituye un modelo bien valorado, en el plano normativo, por los propios militares. Ello no obstante, ya no es posible prescindir de las presiones hacia dinámicas de nuevo tipo. De ahí el interés por comprender en qué punto de la dialéctica entre ambos paradigmas se encuentran más cómodos los profesionales de las armas, en este caso tomando como referente nuestras propias Fuerzas Armadas.

A decir verdad, algunos estudios llevados a cabo por expertos españoles vienen señalando tanto la importancia del asunto como algunas líneas de reflexión que han sido de gran utilidad para trasladar aquellos paradigmas al caso español. Sin ir más lejos, Bañón y Olmeda recuerdan que algunas características estructurales de las modernas FAS de los países más avanzados no son ajenas, claro está, a las nuestras. De modo que también en este caso constituyen un buen punto de apoyo para comprender la presencia de presiones puramente internas hacia dinámicas de convergencia con los ámbitos profesionales civiles. Pensemos en la presencia (creciente) de expertos militares "en áreas tan dispares como la ingeniería, el derecho, la medicina, los sistemas de comunicaciones y de transporte, la educación, el aprovisionamiento..." (Bañón y Olmeda, 1985a: 13). Pero a ese dato hay que añadirle algunas notas peculiares de la evolución, en los últimos años, de las FAS españolas ( $y$, de hecho, de nuestra sociedad, tomada en su conjunto).

Así las cosas, el pasar de unos ejércitos implicados en la disuasión y, llegado el caso, el enfrentamiento con un "enemigo interno", a unos ejércitos cuyo antagonista natural es el "enemigo externo", ha contribuido en gran medida a que las FAS (y sus integrantes) se sientan más receptivas (quizá cabría decir menos recelosas) a las influencias provenientes de una sociedad civil - y de unas instituciones civiles-cuya relación de interdependencia tiende a normalizarse. En este sentido, el aislamiento de otras épocas es abandonado, lenta pero inexorablemente, con los subsiguientes beneficios en términos de convergencia civilinizacional (Bañón y Olmeda, 1985b: 219).

Este proceso está explicado por Martínez Paricio, quien incluye una exposición de sus causas últimas en el tormentoso fin de siglo XIX español, en la desconfianza del militar hacia quienes "dirigen la gobernación de los destinos del país", hasta llegar al punto de que "lo militar ha sido cada vez más extraño en la sociedad" (Martínez Paricio, 1990: 397). Asimismo, este autor enfatiza el flaco favor que se les hizo a las FAS al implicarlas en el desempeño de "un papel de policía contra una población que vivía en sus mismas condiciones" (idem: 402).

Pero Martínez Paricio, como los anteriores, también destaca que desde hace algunas décadas se va produciendo, al principio de manera más solapada, con 
el pasar del tiempo de forma más ostensible, la introducción de valores civilizacionales y, a la postre, ocupacionales, entre los oficiales españoles. Así, en los primeros años de posguerra civil nos hallamos ante una organización carente de medios, de presupuesto reducido y peores sueldos, sustentada sobre valores exclusivamente institucionales, citándose hasta la saciedad una recompensa profesional a duras penas dependiente de algo que no fuese la "satisfacción interior" de las Reales Ordenanzas (Martínez Paricio, 1990: 423). Por contra, ya a finales de los 50 y durante los años 60 , paralelamente a la introducción de nuevas tecnologías y procedimientos (de clara inspiración norteamericana, por cierto) se da un primer paso hacia una modernización medible también en clave sociológica (idem: 425-426). En este sentido, la transición política posterior y el desarrollo económico y social que la acompaña no podían ser sino aldabonazos en la misma dirección.

De hecho, Bañón y Olmeda coinciden en el diagnóstico al apuntar la importancia de tomar en consideración tanto la modernización, digamos técnica, de nuestras FAS, como también los grandes cambios producidos en la España de los sesenta y setenta, con especial énfasis en la nueva relación entre fuerzas sociales y políticas acontecida desde la transición; la paulatina incorporación de nuestro país a un escenario de relaciones internacionales más fluidas y las transformaciones vividas en la propia estructura social española coetáneamente a los procesos descritos (Bañón y Olmeda, 1985a: 317-324).

A pesar de ello, todos los autores mencionados advierten que, en España y por doquier, las organizaciones sociales complejas como la militar (aunque no sólo ella) pueden compatibilizar estas presiones hacia el cambio con otras de tipo distinto, precisamente encaminadas a "aislarse relativamente del entorno para afirmar su singularidad" (Bañón y Olmeda, 1985b: 211), de manera que "la cada vez más compleja división del trabajo y del conocimiento no debería suponer la desaparición de unos valores que son propios de la profesión militar" (Martínez Paricio, 1990: 445). En el presente análisis se toman por buenos estos argumentos pero se intenta, además, analizar y exponer el cómo de esta aparente paradoja (que en realidad no es tal), de acuerdo con la percepción de los principales interesados, que son los oficiales españoles de los tres ejércitos.

\section{La dimensión institucional de las Fuerzas Armadas: su justificación}

En esta línea, lo primero que puede constatarse es que el apego a la dimensión institucional es elevado, por diversos motivos. Las Fuerzas Armadas son vistas como depositarias de unos valores permanentes, dotados de una gran capacidad para salvar los obstáculos que puedan aparecer en cada coyuntura histórica. En algún momento, ese código de conducta aparece casi sacralizado en los textos (Alonso Baquer, 1988: 111). Además, dado su peso específico dentro de los Ejércitos, tiende a crear entre sus miembros una verdadera "uniformidad psíquica", 
RIS

REVISTA INTERNACIONAL DE SOCIOLOGIA

№ 38, MAYO-AGOSTO, 2004

considerada indispensable para fomentar la cohesión intraorganizativa (García Moretón, 1990a: 178).

De hecho, se trata de algo conveniente para lograr uno de los objetivos básicos de cualquier institución - yo diría que una de sus condiciones de posibilidad-, cual es el caso de la estrecha vinculación habida entre los individuos que la integran y el colectivo tomado como un todo. Eso se hace especialmente palpable en la medida que los éxitos y fracasos personales se miden en función de los de la Institución. Y ello no por ninguna imposición externa, sino, ciertamente, debido a la previa interiorización de dicho argumento por parte de los propios militares (De Blas y Osorio, 1985: 31; García Rodríguez, 1989: 1148; García Moretón, 1990b: 640). Por ello, puede afirmarse que los fines de la una y los otros han de ser comunes, así como que la definición de los mismos avanza en sentido vertical descendente y no al revés.

Pero si hasta ahora hemos definido una realidad, no está de más preguntarnos cómo se llega a ella o, incluso, por qué se mantiene ese apego hacia unas tradiciones que a ojos de terceros podrían resultar anacrónicas o, al menos, escasamente comprensibles a la luz de los valores actualmente predominantes. En esta línea, se viene comentando que la milicia posee exigencias específicas, ligadas a su intrínseca marcialidad y a su expresión natural: el fenómeno de la guerra. Desde esta perspectiva, aunque puedan variar las armas, la tecnología, las tácticas o el propio ius ad bellum, se considera que siempre existirá un núcleo duro de reglas de comportamiento - aquello que nosotros podríamos definir como el ethos militar-, de rasgos invariables o, como mínimo, altamente resistentes al cambio (Cabeza Calahorra, 1972: 113).

La razón de ser de esta reflexión estriba en el hecho de que la preparación moral del militar y la asunción de - y hasta el más sincero de los aprecios hacia- virtudes como la disciplina, la lealtad y el honor serían prerrequisitos de obligado cumplimiento para después lograr la eficacia que del conjunto se pretende en el campo de batalla. De este modo, en última instancia, como máxima expresión de este conglomerado axiomático, cabría ubicar esa característica actitud de desinteresado acercamiento a la muerte que suele constituir el colofón de la ética del guerrero (Fernández Areal, 1980: 28).

Se trata, por tanto, de conservar por debajo de la superficie en la que se mueven las innovaciones de todo género, un denominador común que trasciende épocas y naciones. Este denominador común configura lo que de idiosincrático posee la familia militar. Y eso es así, por supuesto, aunque se tome como interlocutores a sus propios conciudadanos. En efecto, en los textos publicados por los propios militares puede identificarse la tendencia a enfatizar que su profesión conlleva un elenco de deberes añadido al que de por sí atañe a los civiles (Aguilar Olivencia, 1976: 78; Martín Jiménez, 1981: 428), hasta llegarse a decir que si bien todos los hombres son iguales en derechos, ello no es óbice para que sean distintos en deberes, ocupando los miembros de las Fuerzas Armadas un lugar de privilegio en lo que a este último aspecto concierne, y con absoluta convicción por cierto (García Dolz, 1984: 167). 
El problema que se plantea en términos sociológicos es que este "diferencial", relativamente fácil de justificar ante el resto de la sociedad en tiempo de guerra, resulta más difícil de asumir por los civiles en épocas de paz. Especialmente si ésta se prolonga en el tiempo. Los militares son plenamente conscientes de ello. Saben de los efectos perversos (incomprensión/desapego sociales) de una situación por otro lado encomiable (paz prolongada). Porque, en tales casos, la tendencia natural lo es a bajar la guardia, al surgimiento de dinámicas individualistas, acomodaticias y hasta despreocupadas. Asumen, también, que en tales casos se acelera la convergencia con los valores de la sociedad civil, incluso por presiones que llegan desde fuera de los cuarteles, precisamente por cuanto desde aquélla deja de apreciarse el valor específico de unas virtudes que pueden llegar a contrariar su propio ideal de la "vida buena" (Laguna, 1987: 135).

Pero, lejos de amilanarse ante tan desfavorable situación, los militares recuerdan lo conveniente que es mantener ese ethos peculiar ante un horizonte que no permite entrever, todavía, el fin de los conflictos bélicos. Al mismo tiempo, advierten de los problemas que podría plantear la opción alternativa, esto es, la asunción acrítica de la etología popular, por cuanto podría llegar a incidir negativamente en la preparación de las Fuerzas Armadas y, llegado el caso, en sus posibilidades de éxito en caso de guerra (Romero Serrano, 1991: 64; Mesa Mesa, 1993: 648; Martín-Pozuelo, 1996: 346; Fuentes Gómez de Salazar, 1997: 273-274).

A partir de dichos argumentos es pertinente llevar a cabo una doble reflexión. En primer lugar, de lo anterior se colige que el mantenimiento de un elenco de virtudes que, a fuer de ser propias de las Fuerzas Armadas, pueden llegar a colisionar con las presentes en la moral social dominante, no se justifica en términos ideológicos, sino en clave funcional. El criterio empleado para legitimar su defensa es, pues, puramente pragmático, ligado como está al tipo de actividad, en sí misma exigente y poco usual, que deben desarrollar los militares.

En segundo lugar, el hecho de que en épocas de relativa calma se siga haciendo hincapié en dicha causa introduce una paradoja, más aparente que real y, en todo caso, fácil de explicar. No es que los miembros de los Ejércitos no sean receptivos ante las nuevas dinámicas culturales. Todo lo contrario, comoquiera que son conscientes de la importancia de esas nuevas dinámicas, tratan de proteger lo que es propio de su mentalidad frente a la indiscriminación moral que lo amenaza. Dicho con otras palabras: probablemente en caso de guerra no sería preciso recordar algo tan elemental, ni mucho menos adoptar ninguna postura "a la defensiva", puesto que la inmensa mayoría de la ciudadanía la haría suya, de modo espontáneo.

\section{Las presiones a favor del modelo ocupacional de Fuerzas Armadas y su integración en el discurso institucionalista}

Las Fuerzas Armadas, como cualquier otra institución, interactúa con las demás organizaciones sociales. Pese a su relativo aislamiento, en alguna medida bus- 
cado por los propios interesados, no es fácil (ni necesariamente positivo) evitar el contacto con los flujos culturales que la envuelven. Es más, puede decirse que la supervivencia de las instituciones como tales también depende de su capacidad de adaptación a los cambios que se desarrollan en su entorno. Por ese motivo, desarrollan cierta capacidad de adaptación, que les permite evolucionar con los nuevos tiempos, y con las nuevas necesidades o retos que se van a ir planteando: "los estudiosos de la historia militar nunca han abrazado la visión estereotipada de que la organización militar moderna es una burocracia rígida, jerárquica e inmodificable. Tanto si los ejércitos y las marinas nacionales se han adaptado mejor o peor a los escenarios cambiantes de la guerra y la paz, raramente permanecieron sin cambiar a nivel organizacional. La historia de la organización militar moderna es una historia de cambios continuos" (Moskos y Burk, 1994: 141). Por tanto, ciertas dosis de flexibilidad pueden ser, no sólo imprescindibles en el terreno empírico, sino hasta bien valoradas en el normativo.

Ahora bien, por nuestra parte se trata de mostrar el modo como se conjugan ambas realidades en el caso concreto de las Fuerzas Armadas españolas. La utilidad del paradigma I/O es notoria en este punto, porque permite analizar la paulatina introducción de pautas ocupacionales sobre la base conformada a priori por los criterios dominantes del modelo institucional vigente. Por lo pronto, es destacable el hecho en sí de que en la literatura segregada por los propios militares ocupe un lugar destacado el debate que adopta como eje vertebrador el paradigma de Moskos. Eso demuestra, además de una apuesta metodológica concreta, una determinada sensibilidad a la hora de afrontar esta cuestión. Pero, como veremos, ello no significa que se adopte a pies juntillas el enfoque del norteamericano, ni que dejen de elaborarse críticas interesantes a sus postulados más elementales.

Lo que sí se palpa es la aceptación de la conveniencia de avanzar por la senda de los enfoques pluralistas de las Fuerzas Armadas. En ese sentido, lo que podríamos definir como la sugerencia básica de Moskos, esto es, la conveniencia de huir de los extremos simbolizados por los modelos institucional/ocupacional tomados en estado puro, es bien recibida por los militares de nuestros tres Ejércitos. Ese es, en sí mismo, un dato relevante. Pero, en realidad, se trata simplemente de una aceptación de la lógica del modelo híbrido de Moskos en su acepción más lata. En efecto, se percibe que este tipo de posturas habrán de permitir la conservación de muchos aspectos del viejo modelo institucional al tiempo que, garantizado lo primero, lejos de cerrar los ojos ante la realidad, se pondera la posibilidad de ir añadiendo a ese bagaje algunas de las modificaciones inducidas por los nuevos tiempos. Sin ir más lejos, se ha comentado que lo plural ofrece la "mejor promesa" para unas Fuerzas Armadas deseosas —es más, necesitadas - de mantener lo mejor de su espíritu, pero sin que ello llegue a ser un obstáculo a la hora de garantizar su apertura ante los cambios que a todos los niveles se van sucediendo - desde el tecnológico hasta el sociológico-político (García Rodríguez, 1993: 739).

Ahora bien, ese buen recibimiento del paradigma y de su potencial (tanto 
explicativo como, llegado el caso, prescriptivo) no puede ocultar los matices - a veces, la oposición radical - que destacados miembros de nuestras Fuerzas Armadas han incorporado al debate sobre el particular, teniendo en el punto de mira el impacto que podría causar la aplicación pura y simple de las conclusiones de Moskos en España. Esto nos obliga a ser cautelosos.

Por una parte, el general Alonso-Baquer, señala - en una línea que podría representar la ortodoxia del paradigma I/O - que lo importante del modelo "híbrido" es la segmentación de las Fuerzas Armadas y, dentro de ella, la "vigencia del segmento institucional entre otros segmentos" (Alonso Baquer, 1988: 137). Pero también opina que el camino a seguir pasa por la adecuada combinación de las lógicas aportadas por cada modelo y, en su caso, otros enfoques complementarios. Así las cosas, llega a teorizar una adaptación del modelo inicial de Moskos -que no una mera transposición del mismo a nuestra realidad-. Esa adaptación, que él denomina como "carrera-oficio", pivotaría sobre unos Ejércitos capaces de retener en su seno "las exigencias éticas de lo institucional, la voluntad de servicio de lo ocupacional y la eficacia de lo burocrático" (ibidem: 129). De esta forma se lograrian evitar las consecuencias de las visiones unidireccionales habidas en cada modelo tomado por separado (entre las cuales destacan los espíritus "pretoriano" y "mercenario", a su entender). Lo significativo del modelo definido por el general es que en él subyace la conveniencia de fomentar cierta "contaminación" (la expresión es mía) de cada segmento de las Fuerzas Armadas (Cuerpo, Arma o unidad) por los elementos característicos de los demás. Por tanto, no está nada claro - todo lo contrario- que agrade la previsión del sociólogo norteamericano en el sentido de que las tendencias actuales lo serían hacia un paulatino distanciamiento entre los diversos segmentos en que cabe descomponer analíticamente a las Fuerzas Armadas.

Este planteamiento, regido por la prudencia, es transformado por otros autores en una denuncia tajante de los riesgos implícitos en las tesis de Moskos. García Moretón, por ejemplo, apunta que de ser ciertos los razonamientos del sociólogo norteamericano, sólo cabe esperar la definitiva "departamentalización" de las Fuerzas Armadas. A su vez, señala que esta evolución puede ser doblemente perjudicial, en la medida en que, además de no contribuir a resolver el problema, siempre latente, de las distancias entre el ethos castrense y los valores de la sociedad civil, más bien multiplicaría las disfunciones internas, al crecer la brecha ya de por sí existente entre diversas unidades militares. Notoriamente, entre las combatientes y el resto (García Moretón, 1990c: 784-786). La imagen que se deduce de ello es la unos Ejércitos rotos por dentro y no por más convergentes con la sociedad civil. Ni que decir tiene que el temor a que esas dinámicas se reproduzcan en la práctica se tornan, una vez trasladadas al discurso, en rechazo. Y, por supuesto, en la sensación de que debe hacerse todo lo posible no ya por acelerar el proceso descrito por Moskos, sino por evitar o disminuir en lo posible sus peores augurios. 
RIS

REVISTA INTERNACIONAL DE SOCIOLOCIA

№ 38, MAYO-AGOST0, 2004

JOSEP BAQUÉS

\section{En busca de una teoría sincrética}

Así, pues, el panorama resultante parece ser un tanto curioso aunque, desde luego, es más que razonable. Por un lado, existe una elevada receptividad ante los conceptos de modelo "plural" o "híbrido" de Fuerzas Armadas, a sabiendas de que ello implica cierta dosis de renuncia, al menos, a la versión más rígida del modelo institucional. Pero, por otro lado, no se asumen con tanta facilidad los efectos colaterales del primero (los derivados de la "segmentación"). Lo que nuestros militares tienen en mente, en definitva, es una suerte de síntesis entre los dos modelos "puros" de los cuales se arranca. Y eso también supone, claro está, que nunca se deben olvidar por completo los valores del modelo institucional, así como la presencia de elevadas dosis de control sobre la inevitable introducción de los que vienen de la mano del modelo ocupacional.

Entonces, ¿cómo se estructura este discurso que lo es de síntesis entre modernidad y tradición?

Para empezar, sobresale el peso que se otorga a la dimensión vocacional de la profesión militar y ello por varios y diversos motivos, que al final tienden a reforzarse mutuamente. Podemos citar los argumentos más usuales vertidos en esta línea.

a) A un nivel muy básico se dice que las propias exigencias de la milicia casarían mal con la mentalidad de quien simplemente busca un empleo para obtener a cambio un sueldo. Esto que se antoja tan elemental en otros casos, es denostado en los textos que tratan este tema. No es que la paga no sea importante, pero queda claro que debe ocupar un lugar secundario en la escala de valores del militar (Clavijo, 1981: 11; Martínez Eiroa, 1986: 1145). De acuerdo con este planteamiento, quien acude a las Fuerzas Armadas atendiendo sólo o principalmente a este tipo de intereses de corte, digamos, individualista, puede encontrarse con la desagradable sorpresa de que ni hallará satisfacción personal ni estará a la altura de lo demandado por la Institución.

b) De modo un tanto más elaborado, se añade que en esta profesión, más que en cualquier otra alternativa, es fundamental que sus miembros actúen atendiendo a unos esquemas morales sólidos y estrictos. Es más, dichos valores no serían algo exógeno a la carrera militar, sino parte integrante de la misma. Por tanto, con carácter general - más allá de las cuestiones pecuniarias - el soldado debe asumir que su trabajo está por encima de las consideraciones materiales (Viseras, 1983: 617; Laguna, 1992: 142; Núñez y Del Real, 1992: 500). Con ello se quiere hacer hincapié en la preceptiva observación de virtudes como la abnegación, el espíritu de sacrificio, la disciplina, etc. La vocación supone, pues, que cada militar debe hacer suyos estos principios hasta ponerlos por delante de cualquier gratificación personal (de hecho, la gratificación se alcanza al comprobar la adecuación de las conductas a lo exigido por estas virtudes).

c) Finalmente, se suele aducir que lo que caracteriza a los Ejércitos no es lo 
que parece evidente a simple vista: la posesión de armas y la preparación para su empleo en acciones bélicas. Eso, en definitiva, también podría ser esgrimido por grupos mafiosos o por mercenarios de todo tipo. Lo verdaderamente idiosincrático de las Fuerzas Armadas es el estilo militar de vida que imbuye a sus miembros (Torres Fernández, 1994: 10; García Moretón, 1997: 12); estilo presidido por una ética y por un espíritu que, convenientemente recogidos en las Reales Ordenanzas, tienen una vigencia de varios siglos (Liberal Lucini, 1992: 33), y que se oponen al "materialismo" y a la "vulgaridad" típicos, precisamente, de quien ha renunciado a esa escala de valores en las sociedades contemporáneas (Laguna, 1995: 27). Esa forma de entender la guerra pone el listón muy alto a la hora de controlar la administración de la violencia o de determinar la asignación de medios a fines. Más bien define y limita los supuestos de su empleo. Y hasta el modo de hacerlo.

Pero, seguidamente, se suele esgrimir que estas consideraciones previas no han de menoscabar la apertura requerida para ir incorporando las novedades que sea menester a la institución militar. Es importante tenerlo presente. Podemos leer artículos en los que se remarca que "en este mundo en que vivimos, ninguna organización puede ser una isla y actuar de forma aislada" (Cea-Naharro, 1994: 89), u otros de similar espíritu en los que el autor se aleja de una disciplina cosificada, convertida en un "valor final", ofreciéndose como alternativa unas Fuerzas Armadas abiertas a la "libertad de pensamiento, de opinión o de decisión de cada individuo" (González Vallejo, 1991: 21), en una artículo que recuerda mucho el paradigma civilinizacional de Janowitz, por un lado, y una voluntad de acercamiento a un funcionamiento de corte más empresarial, por otro lado. $\mathrm{Ni}$ que decir tiene que este tipo de opiniones son más frecuentes a medida que se entra en los años noventa. Lo cual no deja de ser significativo a la hora de identificar tendencias pro-futuro. Pero todo ello, no se olvide, responde a una lógica aplastante.

En efecto, si, tal y como afirmábamos unas líneas más atrás, la justificación del ethos militar es en última instancia antes funcional que ideológica, no tendría mayor sentido su mera "congelación" cuando ello amenazara con socavar la eficacia de las Fuerzas Armadas. Por tanto, la síntesis pergeñada ha de ser lo suficientemente porosa como para admitir la entrada de un importante flujo de transformaciones. Lo que no se concibe desde la óptica militar es que se puedan oponer valores tradicionales y competencia profesional (Parente, 1976: 435; Latorre, 1993: 105). Y, en caso de que se produjera de facto una situación tal, la tendencia lo sería a resolver el entuerto por medio de fórmulas de "encaje" entre ambas corrientes.

Claro que esta afirmación, con ser cierta, podría llegar a sugerir un cuadro marcado por la improvisación. Nada más alejado de la realidad. Si atendemos a las palabras de militares implicados en la labor docente de las diversas Academias militares podremos comprobar que desde la fase de enseñanza se tienen muy 
RIS

REVISTA INTERNACIONAL DE SOCIOLOCIA

№ 38, MAYO-AGOSTO, 2004

JOSEP BAQUÉS

claras las líneas maestras de esta síntesis. Se puede destacar el énfasis en separar la tradición de una presunta "inmovilidad en las ideas", incluyendo entre las notas de modernidad que deben ser incluidas en el erario de la Institución los cambios en la "doctrina" y en la "orgánica" que sean precisos (García Ferrer, 1990: 6 y 7). En otras ocasiones se pone de relieve que las modificaciones introducidas en lo "fundamental e inmutable" deben abarcar "cualquier idea que por los avances tecnológicos, científicos, culturales y sociales se requiera" (Michavila Pallarés, 1977: 793 y 795. El énfasis es mío.) o se afirma, en línea similar, que la única forma de salvar valores y tradiciones es "modernizándose, en lo técnico y material como en lo intelectual y espiritual" (Cano Hevia, 1984: 5. El énfasis es mío.).

Hasta tal punto se tiene claro que estamos ante un esfuerzo dirigido hacia la conciliación de factores en principio distantes, que puede entreverse la tentación de utilizar conceptos distintos para aludir a dichas facetas. Así, por ejemplo, se denomina "formación" a la "iniciación del hombre en la vida militar", es decir, a la divulgación de los contenidos de índole moral, a lo que algunos definen como el ser de la profesión militar (Aranda Carranza, 1979: 1; Martínez Eiroa, 1986: 1145). En cambio, se traen a colación otras nociones, tales como "instrucción" (Aranda Carranza, id) o hasta "información" (Martínez Eiroa, id) para hacer referencia al otro ingrediente, esto es, la preparación técnica, pero también intelectual de los futuros oficiales y suboficiales de nuestros Ejércitos.

Pero lo cierto es que el esfuerzo se está haciendo. De hecho, algunos mandos implicados en la redefinición de los programas docentes vienen destacando ciertos factores que impulsan la apertura de las Fuerzas Armadas ante nuevas realidades, como es el caso de la presencia de la mujer en las Academias. $O$ la necesidad de preparar a los oficiales para actuar en el seno de fuerzas combinadas (esto es, internacionales) a raíz de los crecientes compromisos adquiridos por nuestro país en ese tipo de escenarios (Martínez de Baños, 1994: 53). Pero hasta en los casos en que, como el que se cita, se enfatiza la necesidad de adaptación a los nuevos tiempos, se vuelve una y otra vez sobre la conveniencia de perseverar, también, en la "formación" a la que antes aludía, donde, se dice, "a base de sacrificio y abnegación, formamos un cuerpo y un espíritu de acuerdo con nuestra forma de ser" (idem.).

\section{CONCLUSIONES}

Desde las Fuerzas Armadas españolas se viene asumiendo la necesidad de compensar su dimensión puramente institucional mediante la progresiva asunción de nuevos modos de entender la profesión de las armas. Esto es debido, en buena medida, a que sus miembros están inmersos en unas dinámicas que favorecen la transformación del viejo modelo institucional. En realidad, las influencias que presionan en esta dirección son estandarizables con las existentes en otros 
países de nuestro entorno. Algunas de esas influencias fueron tempranamente detectadas por Janowitz. Otras fueron añadidas por Moskos. Las más recientes forman parte de un emergente paradigma de FAS posmodernas, que a duras penas puede considerarse cerrado. En conjunto, podemos aludir a las siguientes: a) la introducción de nuevas tecnologías; b) la progresiva convergencia con diversos colectivos civiles; c) la reducción del peso de viejos hábitos favorecedores del aislamiento del militar y sus familias; d) la transición hacia un modelo AVF (fuerzas totalmente profesionales); e) la integración de la mujer en todos los Cuerpos y escalas, en igualdad de condiciones; f) el contacto con Fuerzas Armadas de otros países, a raíz de la creciente implicación en misiones internacionales; o g) la propia fisonomía de estas nuevas misiones, en buena parte relacionadas con "operaciones de apoyo a la paz" (por emplear terminología de la OTAN) o, directamente, de ayuda humanitaria. Todo ello conspira contra los puristas" de la lógica institucional.

En concreto, las variables d), e), f) y g) son consideradas, por algunos, como argumentos que favorecen la transición hacia un modelo de FAS que, a fuer de ser ocupacional, es incluso posmoderno. Pues bien, poco a poco el reto se está alcanzando, aunque con más celeridad en unos terrenos que en otros. Y también, como siempre sucede en estos casos, con diferencias nacionales significativas. Pensemos en un caso típico: el nuevo rol de las Fuerzas Armadas en este fin de siglo. No en vano, como señala James Burk, "las fuerzas armadas de los países desarrollados evolucionan hacia la posmodernidad una vez que llegó a estar claro que la guerra ya no era el principal, ni mucho menos el inevitable medio para resolver los conflictos existentes entre ellos" (Burk, 1994: 13). En esta tesitura, como lógico corolario de lo anterior, "la difusión de las fuerzas multinacionales de mantenimiento de la paz, al mismo tiempo que desalienta el uso de la fuerza armada fuera del ámbito de las coaliciones internacionales, limita la tradición de la soberanía nacional, y presiona en favor de la resolución no violenta de los conflictos entre estados y dentro de ellos" (Burk, 1994: 3). Nótese que todo ello puede contribuir a la erosión de los argumentos citados en el epígrafe de este análisis dedicado precisamente a esbozar las líneas maestras de la justificación funcional de la dimensión institucional de las FAS.

Por lo demás, lo decisivo no es tanto que esas variables sean operativas, sino, más bien, que su operatividad sea asumida como algo normal (y hasta deseable) por los propios militares. Así, un lugar común es que "crecientemente, las misiones humanitarias y de mantenimiento de la paz son percibidas como firmemente establecidas dentro del nucleo principal de las misiones militares, en lugar de ser percibidas como una desviación del verdadero proposito de los militares" (Williams, 2000: 266). Quizá porque este proceso tiene mucho de irreversible. Y así se asume por parte de los militares.

Lo cierto es que en el concreto caso español se puede percibir un intento de canalizar esas tendencias de modo que sean digeribles por la Institución, sin trau- 
mas y sin solución de continuidad. Las dos cosas son importantes: tanto el esfuerzo de adaptación como la convicción acerca de la conveniencia de no distanciarse en exceso de los valores tradicionales. De ahí la insistencia en que adaptarse no consiste en renunciar a nada, sino en mejorar lo ya existente a partir de nuevas aportaciones (Fernández Lera, 1992: 120). Es por eso que se aboga por soluciones sintéticas y yo diría que hasta sincréticas, cuya puesta en funcionamiento no tiene por qué ser fácil.

En este sentido, los años ochenta y noventa son años en los que se divulgan y asumen los mensajes de Janowitz y Moskos. En particular, el paradigma I/O de este último es objeto de diversos comentarios en artículos y libros escritos por oficiales españoles pertenecientes a los ejércitos de tierra, mar y aire, indistintamente. Ahora bien, de la lectura de dichos textos se deduce que el segundo término de la síntesis deseada no es exactamente el modelo ocupacional de Moskos. En vez de ello se suele aludir a la idea más abstracta de "modernización". La ventaja que presenta este concepto, un tanto indeterminado, es que da más margen para aceptar algunas reformas y descartar otras. En particular, aquellos cambios que vayan a afectar a los valores y virtudes militares más tradicionales aparecen envueltos en un halo de circunspección.

$\mathrm{Y}$ es que existe una lógica profunda que subyace a esta resistencia, una lógica también transversal a las FAS de los distintos países, pero especialmente arraigada en nuestro caso. En efecto, desde hace bastantes años, los expertos que analizan esta cuestión advierten que, al fin y al cabo, por más especialistas que se integren en las FAS y por más nuevas misiones que se añadan a las clásicas, "la esfera distintiva de la oficialidad es la administración de la violencia" (Van Doorn, 1975: 265). El propio Janowitz había señalado, anticipándose algunos años a la situación vivida en nuestros días, que las FAS del futuro acabarían funcionando a modo de una policía internacional. Pero no deja de advertir que, pese a todo, entre los militares "subsisten —en último extremo- las tendencias a asumir el rol de combatiente/luchador para resolver conflictos" (Janowitz, 1985: 87).

Probablemente, ocurre que "más bien, los roles de combatiente, gestor/técnico, y de militar-estadista/militar-intelectual van siendo sucesivamente añadidos, en lugar de ser sustituidos, a medida que el escenario internacional va cambiando" (Williams, 2000: 268). De ser cierta esta hipótesis, desde luego muy plausible, los respectivos cambios de paradigma en la profesión militar (institucional, ocupacional y, si se desea, posmoderno) poseerían una relación acumulativa, soslayándose en lo posible los juegos de suma cero. Ni que decir tiene que esto incrementa sobremanera la complejidad de la institución militar, obligando a un gran esfuerzo de constante adaptación tanto a los propios militares como, por supuesto, a quienes nos dedicamos a la investigación social extramuros de dicha organización. Pero, más allá de esas dificultades añadidas, así como de los hipotéticos deseos o preferencias de cada cual (deseos y preferencias que, por 
definición, quedan muy alejados de las ciencias sociales), esta imagen compleja posee una carga explicativa muy considerable.

Por este motivo, la noción de pluralidad de modelos que vertebra la obra de Moskos suele ser bien recibida sólo a modo de intuición básica, pero es discutida en su concreción. La segmentación dentro de las Fuerzas Armadas, desde la perspectiva que ha sido objeto de este análisis, posee más inconvenientes que ventajas. No responde bien a los requisitos de la complejidad señalada. Por tanto, la síntesis antedicha tendría que operar dentro de cada unidad. Aunque no es preciso que las dosis respectivas estén repartidas por igual en todas ellas es conveniente que, cuanto menos, aparezcan en unas y otras.

En resumen, todo parece indicar, en primer lugar, que la previsión teórica de esa síntesis concibe unas Fuerzas Armadas que van integrando, con cierta generosidad, los avances derivados del proceso de modernización (doctrinal, orgánica, política y hasta de mentalidad). En segundo lugar, también van integrando, pero con un talante bastante más prudente, aquello que de más específico posee el modelo ocupacional de Fuerzas Armadas (legitimación en términos de mercado/ compensaciones pecuniarias; pérdida de ciertos privilegios corporativos).

Por tanto, yo aludiría a la existencia de una síntesis entre lo institucional y lo ocupacional, pero a sabiendas de que se trata de una sintesis asimétrica, todavia sesgada hacia lo institucional. Por el momento, puede decirse que hemos abandonado el modelo institucional puro sin que ello suponga que se haya abrazado el modelo ocupacional. Más concretamente, puede aducirse que los elementos ocupacionales se van integrando sí, pero de forma lenta y selectiva, en el erario de unas Fuerzas Armadas que durante muchos años se han encontrado cómodas en el paradigma opuesto. El gran reto que tienen planteado las FAS españolas, en este sentido, es el de avanzar por la senda de la posmodernidad sin antes haber cubierto por completo esta etapa intermedia de la inclusión de los valores de perfil ocupacional entre sus cuadros de mando.

En cualquier caso, las conclusiones extraídas de este análisis no poseen el carácter de conclusiones definitivas. Más bien pretenden ser el punto de partida para la construcción de una hipótesis revestida, desde sus orígenes, de un mínimo de plausibilidad. Tienen, en este sentido, un carácter tentativo. Lógicamente, futuras investigaciones podrán corroborar o desmentir, total o parcialmente, lo aquí expuesto.

\section{REFERENCIAS BIBLIOGRÁFICAS}

AGUILAR OLIVENCIA, M. (1976), “La disciplina militar”, Ejército, nº 435 (abril), pp. 77-78.

ALONSO BAQUER, M. (1988), El militar en la sociedad democrática, Madrid, Eudema.

ARANDA CARRANZA, G. (1979), "Perspectivas de la enseñanza naval", Boletin Informativo de Personal, $\mathrm{n}^{\circ}$ especial (enero), pp.1. 
BAÑÓN, R. y J.A. OLMEDA (1985a), La institución militar en el Estado contemporáneo, Alianza Universidad, Madrid.

BAÑÓN, R. y J.A. OLMEDA (1985b), "La investigación social de la organización militar", en Revista de Investigaciones Sociológicas, $\mathrm{n}^{\circ} 43$ (2), pp. 205-225.

BURK, J. (1994), The Military in new times, Oxford, Westview Press.

CABEZA CALAHORRA, M. (1972), La ideologia militar hoy, Madrid, Editora Nacional.

CANO HEVIA, J. (1984), "Discurso inaugural del año académico 1984-85 en la ESE", Ejército no 530 (marzo), pp. 3-9.

CEA-NAHARRO CUENCA, G. (1994), "Reflexiones sobre el liderazgo", Revista Española de Defensa, $\mathrm{n}^{\circ} 75$ (mayo), pp. 89.

CLAVIJO NAVARRO, T. (1981). "De la vocación militar y de otras cosas", en Revista General de Marina, Tomo 200 (Enero), pp. 11-13.

DE BLAS Y OSORIO, J.M. (1985), "El derecho, la Constitución y las Fuerzas Armadas", Revista General de Marina, Tomo 209 (julio), pp. 29-42.

DÍEZ NICOLÁS, J. (1999). Identidad nacional y cultura de defensa, Madrid, Síntesis.

FERNANDEZ AREAL, J.R. (1980), "El futuro de la enseñanza y el fomento de las vocaciones militares", Revista General de Marina, Tomo 199 (julio), pp. 27-30.

FERNANDEZ LERA (1992), "Constitución, Fuerzas Armadas y una mirada hacia el futuro”, VVAA. Posición Constitucional de las FAS en Iberoamérica y en España, Madrid, Tecnos.

FUENTES GOMEZ DE SALAZAR, E. (1997), "Las personas al servicio de la defensa" en H. Oehling (coor), La defensa de España ante el siglo XXI, Fundación Cánovas del Castillo, Madrid.

GARCIA DOLZ, V. (1984), "Patria y profesión militar (sobre la enseñanza militar)", Revista de Aeronáutica y Astronáutica, $\mathrm{n}^{\circ} 518$ (febrero), pp. 165-168.

GARCIA FERRER, C. (1990), “Modernidad y Tradición”, Ejército nº 607 (agosto), pp. 6-7.

GARCIA MORETON, F. (1990a), "El concepto de Institución: su origen y usos", Revista General de Marina, Tomo 218 (febrero), pp. 171-181.

(1990b), "Las Fuerzas Armadas: apuntes para un análisis. Una radiografia de la Institución militar (I)", Revista General de Marina, Tomo 218 (mayo), pp. 631-648.

(1990c), "Las Fuerzas Armadas: apuntes para un análisis. Una radiografia de la Institución militar (II)", Revista General de Marina, Tomo 218 (junio), pp. 775-790.

GARCIA RODRIGUEZ, J. (1989), “Algunas consideraciones sobre la moral y la disciplina”, Revista de Aeronáutica y Astronáutica n 586 (octubre), pp. 1145-1148. 
(1993), "Algunas reflexiones sobre la profesión/condición militar", Revista de Aeronáutica y Astronáutica, $\mathrm{n}^{\circ} 626$ (septiembre), pp. 734-740.

GONZÁLEZ VALLEJO, R. (1991), "Disciplina versus conformismo", Revista Española de Defensa, $\mathrm{n}^{\circ} 45$ (noviembre), p. 21.

JANOWITZ, M. (1985[1975), "Las pautas cambiantes de la autoridad organizativa: la institución militar“, BAÑÓN y OLMEDA (1985a), La institución militar en el Estado contemporáneo (op. cit), pp. 81-99.

(1990[1974), El soldado profesional, Madrid, ed. Ministerio de Defensa, Madrid.

LAGUNA SANQUIRICO, F. (1987), "El militar: ciudadano de uniforme", $R E P \mathrm{n}^{\circ} 56$ (abril-junio), pp. 121-135.

LAGUNA SANQUIRICO, F. (1992), "El espíritu de la Constitución en el marco de las Fuerzas Armadas", VVAA, Posición Constitucional de las FAS en Iberoamérica y en España, Madrid, Tecnos.

LAGUNA SANQUIRICO, F. (1995), "Las escalas de valores", Revista Española de Defensa, n 83 (enero).

LATORRE GIMENEZ (1993), “Reflexiones para la profesión mlitar”, Ejército nº 646 (Noviembre), pp. 105-108.

LIBERAL LUCINI, A. (1992), "Las Reales Ordenanzas para las Fuerzas Armadas", Revista Española de Defensa, $\mathrm{n}^{\circ} 58$ (Diciembre).

MARTIN JIMENEZ, H. (1981), "El deber militar en las Reales Ordenanzas”, Revista de Aeronáutica y Astronáutica $\mathrm{n}^{\circ} 484$ (abril), pp. 427-429.

MARTIN-POZUELO AGUSTIN, V. (1996), "Valores necesarios para vivir la profesión militar", Revista de Aeronáutica y Astronáutica $\mathrm{n}^{\circ} 653$ (mayo), pp. 346-349.

MARTÍNEZ de BAÑOS CARRILLO, F. (1994), "El oficial del futuro”, Revista Española de Defensa, $\mathrm{n}^{0} 79$ (septiembre).

MARTINEZ EIROA, I. (1986), "En torno a la enseñanza militar", Revista de Aeronáutica y Astronáutica $\mathrm{n}^{\circ} 550$ (noviembre), pp. 1145-1148.

MARTÍNEZ PARICIO, J. I. (1990), “Ejército y militares 1898-1998”, en Giner, S. (coor), España. Sociedad y Politica, Barcelona, Espasa-Calpe.

MESA MESA, J. (1993), "Sociedad y Defensa", Revista de Aeronáutica y Astronáutica n 625 (julio-agosto), pp. 645-649.

MICHAVILA PALLARES, F. (1977), "Reflexiones para un nuevo curso", Revista de Aeronáutica y Astronáutica $\mathrm{n}^{\circ} 443$ (octubre), pp. 793-797.

MOSKOS, C. y F. WOOD (1991), Lo militar. ¿Más que una profesión?, Madrid, Ministerio de Defensa. 
MOSKOS, C. y J. BURKE (1994), “The Postmodern Military”, BURK, J. Op. cit., pp. 140-162.

MOSKOS, C., WILlIAMS, J. y D. SEGAL (2000), The Posmodern Military, New York, Oxford University Press.

NUÑEZ BACHES, G. y J. DEL REAL DE LA TORRE (1992), "Reflexiones sobre el concepto doctrinal del militar”, Revista de Aeronáutica y Astronáutica nº 613 (junio), pp. 498-501.

PARENTE, G. (1976), "La técnica, la táctica y la moral”, Revista General de Marina, Tomo 190 (abril), pp. 427-437.

ROMERO SERRANO, J. (1991), “Acerca de la reforma de la enseñanza militar”, Ejército nº17, pp. 52-81.

TORRES FERNANDEZ, J.L. (1994), “La milicia y sus fundamentos”, Revista General de Marina, Tomo 226 (enero), pp. 9-18.

VAN DOORN, J. A. (1975), "The officer corps: A fusion of profesion and organization", European Journal of Sociology, $\mathrm{n}^{\circ}$ 6, pp. 262-282.

VISERAS TALAVERA, F.J. (1983), "Apuntes de interés mutuo para la sociedad civil y las Fuerzas Armadas", Revista General de Marina, Tomo 205 (Noviembre), pp. 613-619.

WILLIAMS, J. (2000), "The Posmodern Military Reconsidered", MOSKOS, C., WILLIAMS, J. y SEGAL, D., The Posmodern Military (op. cit), pp. 265-277. 